\title{
Review Article \\ Human Pluripotent Stem Cell-Derived Cardiomyocytes as Research and Therapeutic Tools
}

\author{
Ivana Acimovic,, Aleksandra Vilotic, ${ }^{1}$ Martin Pesl, ${ }^{1,2}$ Alain Lacampagne, ${ }^{3}$ \\ Petr Dvorak, ${ }^{1,2}$ Vladimir Rotrekl, ${ }^{1}$ and Albano C. Meli ${ }^{1,3}$ \\ ${ }^{1}$ Department of Biology, Faculty of Medicine, Masaryk University, Kamenice 5/A3, 62500 Brno, Czech Republic \\ ${ }^{2}$ ICRC, St. Anne's University Hospital, 60200 Brno, Czech Republic \\ ${ }^{3}$ INSERM U1046, University of Montpellier I, University of Montpellier II, 34295 Montpellier, France
}

Correspondence should be addressed to Vladimir Rotrekl; vrotrekl@med.muni.cz and Albano C. Meli; albano.meli@inserm.fr

Received 6 December 2013; Accepted 4 February 2014; Published 2 April 2014

Academic Editor: Giancarlo Forte

Copyright (C) 2014 Ivana Acimovic et al. This is an open access article distributed under the Creative Commons Attribution License, which permits unrestricted use, distribution, and reproduction in any medium, provided the original work is properly cited.

\begin{abstract}
Human pluripotent stem cells (hPSCs), namely, embryonic stem cells (ESCs) and induced pluripotent stem cells (iPSCs), with their ability of indefinite self-renewal and capability to differentiate into cell types derivatives of all three germ layers, represent a powerful research tool in developmental biology, for drug screening, disease modelling, and potentially cell replacement therapy. Efficient differentiation protocols that would result in the cell type of our interest are needed for maximal exploitation of these cells. In the present work, we aim at focusing on the protocols for differentiation of hPSCs into functional cardiomyocytes in vitro as well as achievements in the heart disease modelling and drug testing on the patient-specific iPSC-derived cardiomyocytes (iPSC-CMs).
\end{abstract}

\section{Introduction}

Cardiovascular diseases are a leading cause of morbidity and mortality in developed countries, causing over 4 million deaths per year just in Europe [1]. They usually result in cardiomyocyte death [2]. Although there are indications that human adult heart has certain level of endogenous regeneration capacity, with different estimations of the rate of cardiomyocyte turnover between studies, adult human heart cannot effectively regenerate after injury [3-6]. Therefore, loss of cardiomyocytes causes permanent damage of heart that progressively decreases its functionality and could eventually lead to heart failure and death. Current treatments of cardiac disorders are mostly based on symptomatic treatment by medications and implantable cardiac devices. While heart transplantation constitutes the ultimate treatment for severe stages of heart failure, there are serious difficulties connected with organ transplantation such as limitations in organ supply and immunological incompatibility. Therefore, providing new tools for treatment of cardiovascular diseases, such as cardiac ischemia, myocardial infarction, and heart failure, is obviously needed. Theoretically, de novo cardiomyocytes for cell replacement therapy could potentially solve the problem of availability of human cardiac tissue.

Human pluripotent stem cells (hPSCs), including embryonic stem cells (ESCs) and induced pluripotent stem cells (iPSCs) are characterized by their ability of unlimited selfreplication and differentiation. Takahashi et al. first succeeded to reprogram human adult somatic cells to a pluripotent state [7]. They used forced overexpression of four transcription factors (OCT3/4, SOX2, KLF4, and $c-M Y C)$ delivered by retroviral vectors for induction of pluripotent state in adult dermal fibroblasts. Generated hiPSCs exhibited essential hESC-like properties regarding morphology, proliferation, pluripotency markers, and gene expression. Also, hiPSCs showed the ability to differentiate to cell types of all three germ layers in vitro and in vivo [7]. In the following years, reprogramming techniques have been improved. It has been shown that human fibroblasts, keratinocytes, lymphocytes, and even more recently urine-derived cells can be reprogrammed in iPSCs with relative efficiency of reprogramming and subsequent differentiation [8-12]. Using 
oncogenic transcription factors such as $c-M y c$, viral vectors, and occurring random transgene insertions into the host's genome during reprogramming raised concerns of hiPSCs tumorigenicity and safety of using hiPSCs for clinical applications.

Teratoma formation is one of the desired properties of PSCs demonstrating their ability to differentiate $[13,14]$. Teratocarcinogenicity is a pathological property of PSCs when they do not differentiate in the in vivo environment. Possible occurrence of dangerous teratocarcinoma is the dark side of PSC potential use in the cell therapy $[15,16]$. Teratocarcinogenicity is an intrinsic property of mouse ESCs due to their proliferative capacity and it is a consequence of epigenetic transformation of ESCs to embryonic carcinoma cells (ECCs) [13], while normal human ESCs do not readily form teratocarcinoma in immunodeficient mice and the transformation to human ECCs requires genomic changes (i.e., mutations) $[17,18]$. Thus, unless hESCs are aneuploid, the residual undifferentiated cells are likely to form benign tumors only. Also the ability of iPSCs to create tumors seems to correspond to the level of genomic stability [19].

The hiPSCs created using viral vectors were shown to have elevated mutant frequencies and aberrant epigenome compared to hESCs or even differentiated cells [20], suggesting lower genome stability and thus higher risk of cancer development. Transplantation of progenitors or even terminally differentiated cells derived from pluripotent cells raises hopes for cell replacement therapy as PSC-derived differentiated cells similarly to mouse embryos after neurulation lose their ability to create teratocarcinoma and rather form benign teratomas [21]. But so far it is not technically possible to generate pure populations of terminally differentiated cells without traces of progenitors/stem cells. These data altogether suggest that finding reprogramming methods leading to lower mutant frequencies and higher genome stability might significantly contribute to the safety of iPSC products. Equally important is finding differentiation protocols leading to more defined and clearer populations of terminally differentiated cells intended for cell replacement therapy or development of robust transdifferentiation protocols eliminating the need and danger of PSCs.

To decrease tumorigenic potential different methods of generating hiPSCs were developed, including different combinations of reprogramming genes [22, 23] together with small molecules [24], which increased reprogramming efficiency, and use of different excisable $[11,25,26]$ or nonintegrative vectors [27] for delivering reprogramming factors. A step forward to virus-free reprogramming methods was application of synthetic-modified mRNA [28] and recombinant proteins [29-31]. Therefore, application of improved reprogramming protocols for hiPSC generation, which will be safe for clinical use and production of patient-specific iPSC-derived cardiomyocytes (iPSC-CMs), would theoretically overcome immunological complications of transplanting organs and enable avoiding immunosuppressive treatment.

Differentiation of hPSCs to cardiomyocytes can be achieved in vitro by modulation of signalling pathways that are involved in cardiac development during embryogenesis. Potential applications of hPSC-CMs are numerous but the main goal is to get the highest output under the controlled culture conditions while major limits are low efficiency of current protocols and cardiac population heterogeneity (i.e., nodal, atrial, and ventricular cardiomyocytes). In the present discussion, we summarize the state-of-the-art methods for generating cardiomyocytes from hPSCs and their potentials as research and therapeutic tools.

\section{How to Generate De Novo Cardiomyocytes from hPSCs}

2.1. Cardiac Differentiation through Coculture with END-2 Cells. One of the first protocols for directed cardiomyogenesis of hESCs was developed by Mummery and colleagues and involved coculture of hESCs with mouse visceral-endodermlike cells (END-2) [32]. Endoderm-secreted factors, such as bone morphogenetic proteins (BMPs), nodal/activin A, fibroblast growth factors (FGFs), and repressors of canonical Wnt $\beta$-catenin pathway, have direct role in cardiac differentiation of hESCs. Overall efficiency of this protocol to generate hESC-CMs is quite low, resulting mostly in ventricular-like cardiomyocytes. Improvement of this protocol was achieved by switching from $20 \%$ fetal calf serum (FCS) in the medium to the serum-free conditions and by addition of L-ascorbic acid [33]. Similar protocol has been successful also to obtain hiPSC-CMs [34]. Decrease of FCS concentration led to increased percentage of beating areas in a dose-dependent manner and resulted in a 39-fold increase in total number of cardiomyocytes in the serum-free medium. Cardiac differentiation was further promoted in the insulin-free conditions. Phosphatidylinositol 3-kinase (PI3K) signalling inhibition increased the expression of mesendoderm markers [35], while insulin redirected differentiation in favour of neuroectoderm [36]. Enhancement of cardiac differentiation by ascorbic acid has also been shown in mouse PSCs (mPSCs) [37], through promotion of cardiac progenitor cell proliferation [38].

2.2. Embryoid Body-Based Cardiac Differentiation. Embryoid body-based method involved culturing of hPSCs as threedimensional cell aggregates called embryoid bodies (EBs). Initially, after collagenase IV treatment small hPSC clumps were cultured in suspension to form EBs in the medium with $20 \%$ FBS. After 7-10 days EBs were plated on the gelatincoated culture dishes, which gave $8.1 \%$ of spontaneously beating EBs [39]. The imperfection of the protocol with FBS is that interbatch differences of FBS can have significant impact on the efficiency of cardiac differentiation [40]. However, it seems that FBS enables cardiac differentiation in EB-mediated protocol in endoderm-dependent manner [41]. Addition of 5-aza- $2^{\prime}$-deoxycytidine but not DMSO nor retinoic acid significantly enhanced cardiac differentiation of hESCs [42]. After induction of cardiac differentiation of EBs 
in FBS-containing medium, EBs can be kept in the defined medium without serum [43].

Sometimes there is an intermediate step in the evolution of the protocols that mix two basic approaches and make it difficult to draw a clear line between methods. One of them includes differentiation of hESC-EBs in the serum-free END2 conditioned medium [44]. It was shown that cardioinductive effect of END-2 cells was independent of the direct interaction between hESCs and END-2 cells [45]. In the same study insulin was found as an inhibitor of cardiomyogenesis in concentration-dependent manner predominantly during the early phases of differentiation, whereas prostaglandin I2 (PGI2) was discovered as enhancer. Cardiac differentiation of hESC-EBs in serum-free END-2 conditioned medium yielded $10 \% \mathrm{CMs}$ in the overall cell population with an increase to $20 \%$ by use of SB203580, specific p38 mitogenactivated protein kinase (MAPK) inhibitor, and resulted in approximately equal proportion of atrial- and ventricular-like cardiomyocytes [46].

Efforts that have been put to improve EB-based cardiac differentiation of hPSCs led to higher efficiency of the protocols through application of specific growth factors and chemically defined media and formation of uniform-sized EBs.

2.2.1. Specific Growth Factors and Small Molecules. Application of various combinations of specific growth factors in concentration- and time-dependent manner during cardiac differentiation of hPSCs in vitro can mimic signalling pathways responsible for cardiomyogenesis during embryonic development in vivo. Short-term BMP4 treatment promotes mesoderm induction [47], while long-term treatment leads to trophoblast [48] and extraembryonic endoderm differentiation [49]. Inconsistence in cardiac differentiation efficiency due to the interbatch differences of FBS used in the culture medium can be partially overcome with addition of BMP4 [40].

Canonical Wnt/ $\beta$-catenin pathway has a biphasic role in human cardiogenesis. It should be activated during the early phase and inhibited during the late phase of cardiac differentiation [50]. Activation of Wnt signaling during the early phase of cardiac differentiation in hPSC-EBs by application of Wnt activators (Wnt3a, BIO, and CHIR99021) can be crucial for mesoderm induction $[51,52]$. Early treatment with BMP4 followed by Wnt signalling inhibition, using inhibitor of Wnt response 1 (IWR1) or inhibitor of Wnt production 1 (IWP1), increases the efficiency of BMP4-directed cardiac differentiation of both hESCs and hiPSCs [53]. Some other small molecule inhibitors of Wnt pathway (i.e., IWP3, 53AH, and XAV939) also showed cardiogenic effect when applied after BMP4/activin A-mesoderm induction in hESC-EBs [54]. Use of stage-dependent combinations of BMP4, activin A, FGF2, Dickkopf 1 (DKK1), and VEGF in serum-free media and maintaining EBs under hypoxic conditions $\left(5 \% \mathrm{O}_{2}, 5 \% \mathrm{CO}_{2}\right.$, and $90 \% \mathrm{~N}_{2}$ ) during the first 12 days of differentiation resulted in approximately $70 \%$ beating EBs [55]. After mesoderm induction, inhibition of TGF $\beta /$ activin/nodal and BMP4 signalling with small molecules SB431542 and dorsomorphin, respectively, can improve this system [56]. It was noticed that for each cell line it was necessary to optimize the protocol as different cell lines can differ in the levels of endogenous signalling. Our group also observed the interline variability in the cardiac differentiation efficiency as we applied the same growth factors (with substitution of DKK1 with IWR1) in the FBS-containing medium [57]. Seeking for more potent small molecule that could promote cardiac differentiation of hPSCs under defined cytokine- and xeno-free conditions, Minami et al. discovered KY02111, small molecule that acts as a Wnt inhibitor [52]. They also found as requirement for cardiac differentiation in the serum-free medium an addition of $0.4 \%$ human serum albumin or $1-2 \%$ bovine serum albumin. Recently, trichostatin A, histone deacetylase inhibitor, has been found as enhancer of EB-mediated cardiac differentiation [58].

2.2.2. Controlled EB Size. Studies on mESCs have shown that EB size and density were crucial for cardiac differentiation efficiency $[59,60]$. The outcome of the EB-mediated differentiation of hESCs also depended on the size of the EBs [61]. Thus, some of the protocols included a step of forced aggregation of defined number of single hPSCs in the multiwell plates (96-, 384-well) [62] that eventually finished in homogeneous EB population. Stability of the aggregates was promoted by application of the Rho-associated protein kinase (ROCK) inhibitor, Y-27632 [62, 63]. Efficient EB formation was observed in U-, V-bottom well plates [64, 65], as well as AggreWell plates [57]. Stage-specific application of defined growth factors, polyvinyl alcohol, serum and insulin in the combination with V-96 plate aggregation system led to $94.7 \%$ of beating EBs and eliminated an interline variability in cardiac differentiation [66].

2.3. Monolayer-Based Cardiac Differentiation. High-density undifferentiated monolayer of hESCs on matrigel-coated culture dishes [67] or bone sialoprotein-peptide acrylate surface (BSP-PAS) [68] can be differentiated into cardiomyocytes by combined application of activin A and BMP4 in Roswell Park Memorial Institute (RPMI) 1640 medium plus B27 supplement resulting in more than 30\% cardiomyocytes [67]. In the same way as in the EB-mediated differentiation, addition of Wnt3a in the early phase of activin A/BMP4-directed cardiac differentiation, as well as inhibition of Wnt/ $\beta$-catenin signalling with DKK1 in the late stage, can enhance cardiac differentiation of hESCs [69]. Inhibition of Wnt pathway with IWR1 resulted in mostly atrial-like cardiomyocytes whereas inhibition with IWP4 gave both ventricular- and atrial-like cardiomyocytes based on expression of myosin light chain isoforms (MLC2v and $M L C 2 a$ ) [70]. The percentage of ventricular-versus atriallike cardiomyocytes can be also modulated by alternation of retinoid signalling [71]. Further improvements involving matrix sandwich (overlay of monolayer-cultured hPSCs with matrigel), removal of insulin, and addition of FGF2 [72] resulted in up to $98 \% \mathrm{CMs}$, mainly ventricular-like [73]. In fully chemically defined medium (serum- and insulinfree) only by pretreatment with glycogen synthase kinase 3 
(GSK3) inhibitor and modulation of Wnt pathway with $\beta$ catenin shRNA or chemical Wnt inhibitors (IWR2, IWP4) it is possible to produce a high yield of hPSC-CMs [74]. Interestingly, using monolayer-based protocol on hPSCs, Lian and colleagues pointed out the network existing between insulin and $\mathrm{Wnt} / \beta$-catenin signalling pathways during cardiac mesoderm $(\mathrm{Nkx} 2.5+)$ stage. Their work revealed the importance of the $\mathrm{Wnt} / \beta$-catenin signalling to be dominant to the insulin pathway to influence hPSC differentiation to cardiomyocytes [75].

\section{Large-Scale Cultivation of hPSC-CMs}

Reproducible production of high number of hPSC-CMs is crucial for therapeutic and biopharmaceutical applications. It also requires a high number of starting hPSCs that have been achieved in suspension culture [76-79] and by use of bioreactors [80-83]. Although use of bioreactors offers optimization and control of key bioprocess parameters (e.g., temperature, oxygen tension, and $\mathrm{pH}$ ), there are issues such as maintenance of high pluripotency level and karyotype stability of hPSCs in suspension system.

In the first place bioreactors were used for large-scale production of mouse ESC-CMs $[84,85]$. Human ESC-CMs were generated through formation of large number of sizedefined hESC aggregates by employing a micropatterning strategy [86] or microencapsulation technology [87] in combination with fully controlled bioreactor system. For efficient EB proliferation, prearrangement in the static culture prior to seeding into the stirred systems could solve a problem of extensive agglomeration of hESC-EBs in dynamic systems [88]. In spite of the fact that use of bioreactors enables generation of high amount of hPSC-CMs, it is necessary to improve methods for their further purification.

\section{Cardiac Tissue Engineering and hPSCs}

In vitro models of cardiac tissue based on two-dimensional cell culture conditions do not completely mimic its properties. The aim of cardiac tissue engineering is to create artificial tissue with morphological and functional properties similar to native myocardium [89] which can be used as model in developmental biology studies and drug screening [90], as model for developing functional tissue replacement for heart failure patients [91, 92], or for modelling cardiac disorders with complex etiology.

Different approaches to cardiac tissue engineering have been developed. The most extensively used ones are cultivation of scaffold-free stackable cell sheets $[93,94]$, mechanical stimulation of cells in hydrogels $[91,95]$, cell cultivation on perfused channelled scaffolds [96-98], electrical stimulation of cells in porous scaffolds [99-101], and repopulation of decellularized native tissue $[102,103]$.

The first human-based engineered cardiac tissue was done by seeding hESC-CMs together with human vascular endothelial cells and fibroblasts on porous poly-L-lactic and polylactic-glycolic acid scaffolds [104]. The Murry group used scaffold-free approach to generate hESC-derived cardiac tissue patches [105]. In this research they showed that patches made from hESC-CMs, endothelial cells, and fibroblasts had significantly higher viability and physiological function after transplantation compared to patches based on enriched cardiomyocytes alone $[105,106]$. Later researches demonstrated importance of cardiac fibroblasts for formation of functional ESC-derived engineered cardiac tissues [107, 108]. First successfully engineered functional human heart tissues by repopulating intact decellularized mouse heart were done by seeding hiPSC-derived multipotential cardiovascular progenitors [102].

For potential clinical applications cardiac tissue engineering requires large number of cells ( $>10^{8}$ cells/patient/patch); that is why large scale production of hiPSC-CMs needs to be developed. Also, it is necessary to provide methods for obtaining pure population of hPSC-CMs which will be completely free from undifferentiated stem cells. Although cardiomyocytes derived from hPSCs usually show immature phenotype $[109,110]$ which could be also a limiting factor for clinical applications of hPSC-CM patches, it has been shown that engineered cardiac tissues can improve functional maturation of hESC-CMs [111].

\section{Direct Transdifferentiation and Conversion of Somatic Cells to Cardiomyocytes}

Although the understanding of the molecular control of transdifferentiation is unclear, it turned out that, through gene regulation and specific pathways activation/inhibition, noncardiac somatic cells can shift over epigenetic fate and convert to CMs without any pluripotent stem cell intermediate. In 1987, Davis et al. originally described this process of transdifferentiation by converting fibroblasts to skeletal myoblasts using a single transfected cDNA [112]. Similar strategy has been then used in transdifferentiation of fibroblasts to other cell types as neurons [113-115], hepatocytes $[116,117]$, mouse CMs [118], and more recently human CMs $[119,120]$.

Mouse cardiac and dermal fibroblasts can be transdifferentiated into CMs in vitro with three basic factors, Gata4, Mef2c, and Tbx5 (GMT) [118, 121, 122]. The resulting CMs exhibited spontaneous calcium oscillations and only partially resembled adult CMs [123]. GMT turned out to be insufficient to convert somatic human cells, and addition of Mespl and Myocd factors to GMT (GMTMM) triggered a human cardiac phenotype, upregulated a broader spectrum of cardiac genes, and suppressed fibroblast genes [120].

Fibroblast transdifferentiation can thus circumvent the induction and subsequent differentiation during generation of hiPSC-CMs and may also shift the paradigm of limited cardiac regeneration capacity [124-126]. Large amount of native cardiac fibroblasts can serve as a source for CM derivation needed not only for further basic research, but also for cell replacement therapy and regenerative medicine. However, despite optimistic initial steps, the transdifferentiation to fully mature and functional CMs needs further investigations and 
a better evaluation of their ability to coexist in an organ like the heart.

\section{Degree of Maturity of hPSC-Derived Cardiomyocytes}

Human PSC-CMs exhibit different level of structural and electrophysiological maturity. Thus, several groups recently characterized the molecular, structural, and functional features of the resulting hiPSC-CMs [127-129]. Although signs of immaturity are clearly visible at early stage of differentiation, it turns out that hiPSC-CMs, when maintained in culture in vitro for a prolonged period of time, slowly exhibit maturation with phenotypic features that resemble those of adult human CMs.

Cardiovascular disorders, especially heart failure, are complex diseases of mature vascular system and myocardium. Pathophysiological processes including the loss of mechanical function and/or altered electrophysiology are usually associated with adult cardiomyocytes. Although inherited diseases (e.g., channelopathies) can present their phenotype in early stage of cardiomyocyte development, there are differences in pathophysiology of the electrical conduction, electromechanical coupling, and mechanical contraction during various stages of development. For example, cells of the primary cardiac tube show action potentials resembling those of the adult pacemaker cells but showing slow depolarization, associated with slow voltage-gated calcium ion channels (absence of fast sodium channels) [130]. Moreover, other populations contribute to the heart development in different times such as Isll expressing cells from the dorsal coelomic wall [131] or Tbx positive cells [132], inevitably resulting in mixed population of cells in various stages of maturity.

Assessment of maturity was often discussed in connection with hPSC cardiac differentiation but is not widely standardized. Immature phenotype can be excluded by the use of pluripotency and mesenchymal markers such as stagespecific antigen 1 (SSEA1) and mesoderm posterior 1 (MESP1) [133] or cardiac progenitor markers LIM, homeodomain transcription factor Isl1 [131] and homeobox protein Nkx-2.5 [134].

Maturity is closely related also to $\mathrm{Ca}^{2+}$ handling as caffeine-sensitive intracellular calcium stores were shown to be increasing from the initiation of beating in hESC-CMs through the next 30 days [109].

Therefore, the level of maturity of the hiPSC-CMs could be of great importance for the researches based on models of late-onset cardiac diseases. Additional stimuli upon differentiation that enable both electrical stimulation and mechanical stretching, mimicking heart environmental stimuli, certainly improve the maturity and functionality of those iPSC-CMs [135]. In the context of sarcomeric organization, uniaxial mechanical stress conditioning promotes further increases in cardiomyocyte and matrix fiber alignment and enhances myofibrillogenesis and sarcomeric banding [136].

\section{Human Induced Pluripotent Stem Cells, Cardiac Disease Modelling, and Drug Testing}

Since cardiovascular diseases are one of the leading causes of mortality and morbidity worldwide, it is of great importance to improve our understanding of underlying pathophysiologic mechanisms and to develop better treatments. The majority of researches on molecular mechanisms causing cardiac disorders were done on animal models. Although they greatly contributed to our knowledge, using animal models has serious limitations because of human genome specificity and considerable difference between cardiac physiology in humans and the usual model animals. For further research and progresses in this field it was necessary to develop human cardiac disease models in vitro. Possibility of generating patient-specific iPSC-CMs revealed new opportunities for biomedical research on mechanism of genetic cardiac disease pathogenesis and also for discovery of new drug treatments.

Electromechanical coupling is essential for the correct functioning of the heart. It requires coordinated interaction of cardiac ion channels and contractile proteins. A single mutation in genes coding these proteins can cause abnormalities in either electrical stimulation (channelopathies) or generation of the force in heart muscle (cardiomyopathies). Using patient-specific iPSCs, it is feasible to model genetic cardiac disorders such as channelopathies and cardiomyopathies in vitro (see Table 1 for a summary of genetic cardiac disorder modelling).

In 2010, Carvajal-Vergara et al. described for the first time a human model of LEOPARD syndrome (an acronym formed from its main features, that is, lentigines, electrocardiographic abnormalities, ocular hypertelorism, pulmonary valve stenosis, abnormal genitalia, retardation of growth and deafness), with life-threatening hypertrophic cardiomyopathy as one of major disease phenotype characteristics [137]. This study was carried out by generating iPSC lines from two LEOPARD syndrome patients and by using a defined protocol to derive cardiomyocytes [55]. In the same year, Moretti et al. reported long-QT syndrome type 1 modelling using patient-specific iPSC-CMs that exhibited electrophysiological properties of this disorder [138]. Since then, the number of reported hereditary cardiac disease models based on patient-specific iPSCs has greatly increased [139-153]. Interestingly, a familial form of dilated cardiomyopathy due to mutation in the sarcomeric troponin $\mathrm{T}$ protein, was also modelled using hiPSC-CMs [150]. While the authors were able to reproduce some phenotypic features of the disease, including altered regulation of intracellular $\mathrm{Ca}^{2+}$, decreased contractility and impaired sarcomeric organization, they also succeeded to improve the function of the mutant cells with overexpression of sarcoplasmic reticulum $\mathrm{Ca}^{2+}$ adenosine triphosphate (SERCA2a), a major actor of the intracellular calcium handling.

Although the abovementioned studies support the concept of disease modelling by using hiPSC-CMs, there are some challenges. One critical step is identifying diseaserelevant phenotypes. Therefore, it is of great importance to 
TABLE 1: Summary of genetic cardiac disorders that have been modeled using hiPSC-derived cardiomyocytes, including drugs that have been tested.

\begin{tabular}{|c|c|c|c|c|}
\hline Cardiac disease & Affected gene & Mutation & Rescue, drug testing & References \\
\hline \multicolumn{5}{|l|}{ Channelopathies } \\
\hline \multirow[t]{2}{*}{ LQT1 } & KCNQ1 & p.R190Q & Propranolol & {$[138]$} \\
\hline & & p.P631fs $/ 33$ & Propranolol & {$[139]$} \\
\hline \multirow[t]{5}{*}{ LQT2 } & $\mathrm{KCNH} 2$ & p.A614V & Nifedipine, pinacidil, ranolazine & {$[140]$} \\
\hline & & p.A561T & Propranolol, nicorandil, PD-118057 & {$[141]$} \\
\hline & & p.R176W & Erythromycin, sotalol, cisapride & {$[142]$} \\
\hline & & p.G603D & N/A & {$[154]$} \\
\hline & & p.A561T & Mutation-specific siRNAs & {$[155]$} \\
\hline \multirow[t]{2}{*}{ LQT3 } & SCN5A & p.1795insD & $\mathrm{N} / \mathrm{A}$ & {$[143]$} \\
\hline & & p.V1763M & Mexiletine & {$[156]$} \\
\hline Timothy syndrome (LQT8) & CACNA1C & p.G406R & Roscovitine & {$[144]$} \\
\hline \multirow[t]{6}{*}{ CPVT1 } & RYR2 & p.F2483I & $\mathrm{N} / \mathrm{A}$ & {$[145]$} \\
\hline & & p.S406L & Dantrolene & {$[157]$} \\
\hline & & p.M4109R & Flecainide, thapsigargin & {$[146]$} \\
\hline & & p.P2328S & $\mathrm{N} / \mathrm{A}$ & {$[147]$} \\
\hline & & p.Q231D & $\mathrm{KN}-93$ & {$[148]$} \\
\hline & & p.F2483I & N/A & {$[158]$} \\
\hline CPVT2 & CASQ2 & p.D307H & $\mathrm{N} / \mathrm{A}$ & {$[149]$} \\
\hline \multicolumn{5}{|l|}{ Cardiomyopathies } \\
\hline LEOPARD syndrome & PTPN11 & p.T468M & N/A & {$[137]$} \\
\hline DCM & TNTT2 & p.R173W & SERCA2a, metoprolol, norepinephrine & {$[150]$} \\
\hline $\mathrm{HCM}$ & MYH7 & p.R663H & PVNDLMR $^{\#}$ & [159] \\
\hline ARVC & РКР2 & p.L614P & N/A & {$[151]$} \\
\hline
\end{tabular}

\#PVNDLMR: propranolol, verapamil, nifedipine, diltiazem, lidocaine, mexiletine, and ranolazine.

choose appropriate control lines to which patient-derived lines will be compared. Although iPSC lines derived from a healthy unrelated or related person are usually used as control [137-159], the best choice would be a line in which the mutation causing the disorder is corrected. In that case the presence of phenotypic differences between the patient's iPSC-CMs and the cardiomyocytes derived from the "corrected" line would confirm that those differences are caused by the mutation per se as recently has been shown by Bellin et al. working on cardiac channelopaty model [160]. Different genome editing methods have been used for correcting mutations in patient-specific iPSCs such as using engineered nucleases with or without DNA repair templates [161-163], enabling research in genetically defined conditions which gives a real potential for improved hiPSCbased disease modelling.

As mentioned before, hiPSC-CMs usually exhibit incomplete maturity properties which may affect their suitability for drug screening and modelling late-onset cardiac diseases. Additionally, cardiac differentiation potential differs between different hiPSC lines [11, 164] which could slow down researches dependent on high amount of de novo cardiomyocytes, especially high throughput drug screening.

7.1. Cardiac Channelopathies. Ion channels are pore-forming, transmembrane proteins which regulate ion fluxes across the membrane. Coordinated opening and closing of voltagegated ion channels generate action potential in cardiomyocytes. Cardiac channelopathies are a group of cardiac diseases caused by mutations in genes encoding ion channels that lead to impaired electrical activity of the heart.

7.1.1. LQTS. The long-QT syndrome (LQT) represents a group of cardiac channelopathies characterized by delayed depolarization of the heart. Patients with long-QT syndrome show prolonged QT interval on an electrocardiogram and have high risk of sudden cardiac death due to susceptibility to polymorphic ventricular tachyarrhythmias, in particular torsades de pointes. Mutations in genes encoding ion channels involved in the ventricular depolarization are causing long-QT syndromes. The prevalence of LQT in Caucasian population is estimated to be $1: 2000$ [165]. At least 12 types of LQT syndrome have been described [166] and some of them have been modelled by using patient-specific iPSC-CMs.

LQT1. Type 1 long-QT syndrome is an autosomal dominant cardiac disorder. Mutation in KCNQ1 encoding $\alpha$ subunit of the $\mathrm{K}^{+}$channels responsible for $I_{\mathrm{Ks}}$, that is, the slow component of the delayed rectifier potassium current sensitive to adrenergic stimulation, leads to LQT1. Moretti et al. were the first who described an in vitro model of type 1 long-QT syndrome by generating iPSCs from two related 
asymptomatic patients and subsequently differentiating them to cardiomyocytes [138]. Derived LQT1-specific CMs exhibited characteristic disease phenotype such as significantly longer action potentials (APs), less pronounced adaptation of APs to higher pacing frequencies compared to control, and elicitation of arrhythmic-like events under isoproterenol treatment which were attenuated by $\beta$-blockers.

LQT2. Long-QT syndrome type 2 is caused by mutations in $\mathrm{KCNH} 2$ encoding $\alpha$ subunit of the hERG $\mathrm{K}^{+}$channel generating the rapid component of the delayed rectifier potassium current $\left(I_{\mathrm{Kr}}\right)$. Itzhaki et al. reported in vitro model of LQT2 syndrome by using patient-specific iPSC [140]. Derived hiPSC-CMs, which exhibited typical disease phenotype characteristics such as prolonged AP and presence of early afterdepolarizations (EADs), were used also for studying the effects of different therapeutic agents on preventing arrhythmias. Shortening of AP and prevention of EADs were accomplished by application of nifedipine, an L-type $\mathrm{Ca}^{2+}$ channel inhibitor which blocks contribution of $\mathrm{Ca}^{2+}$ influx to AP duration and formation of EADs, or by application of pinacidil, an $I_{\mathrm{K}, \mathrm{ATP}}$ channel opener which increases repolarization currents. However, application of ranolazine, a late $\mathrm{Na}^{+}$channel blocker, prevented EADs but did not shorten the AP duration.

LQT2 syndrome was also modelled by reprogramming somatic cells from mother and daughter carrying the missense mutation in $\mathrm{KCNH} 2$ [141]. Although both patients carried same mutation and had prolonged QT interval, the daughter experienced arrhythmias previously while mother did not experience any symptoms. Cardiomyocytes derived from both patients showed characteristic disease phenotype although, it was less pronounced in maternal iPSC-CMs comparing to daughter's iPSC-CMs. Also, data from this study suggested that application of potassium channel activators such as nicorandil, an $I_{\mathrm{K}, \mathrm{ATP}}$ channel opener, and PD-118057, an $I_{\mathrm{Kr}}$ channel enhancer, shortened AP duration and had antiarrhythmic effect on LQT2-hiPSC-CMs. Another research from the same group reported a potential novel patientspecific therapy for LQT2 patients by allele-specific mRNA knockdown of mutated hERG protein [155].

Additionally, several groups showed that patient-specific iPSC-CMs derived from individuals without severe symptoms or with the novel mutations could also be used for studying basic pathology of LQT syndrome and drug screening, and for personalized medicine in the future $[139,142,154]$.

LQT3. Long-QT syndrome type 3 is caused by gain-offunction mutations in SCN5A encoding $\alpha$ subunit of the cardiac $\mathrm{Na}^{+}$channel. These mutations increase persistent $\mathrm{Na}^{+}$current $\left(I_{\mathrm{Na}}\right)$, which causes prolonged repolarization in cardiomyocytes and longer action potential. However, mutations in SCN5A connected with loss-of-function of sodium channel cause Brugada syndrome $(\mathrm{BrS})$ characterized by decreased peak in $I_{\mathrm{Na}}$ and reduced upstroke velocity of the AP.

An overlap syndrome with clinical features of LQT3 and $\mathrm{BrS}$ was modelled by iPSC-CMs derived from a patient carrying the SCN5A-1795insD mutation [143]. LQT3-specific CMs exhibited a characteristic disease phenotype caused by both gain- and loss-of-function of $\mathrm{Na}^{+}$channel. Recently, another group reported the modelling of LQT3 syndrome based on iPSC from a patient carrying a mutation in SCN5A [156]. LQT3-hiPSC-CMs showed prolonged AP, which was successfully shortened by application of mexiletine, a $\mathrm{Na}^{+}$ channel blocker.

LQT8 (Timothy syndrome). Yazawa et al. studied iPSC-CMs from two patients with Timothy syndrome associated with the missense mutation G1216A in CACNA1C gene encoding the $\alpha$ subunit of the L-type $\mathrm{Ca}^{2+}$ channel [144]. Timothy syndrome-specific cardiomyocytes exhibited delayed inactivation of $I_{\mathrm{Ca}, \mathrm{L}}$ and abnormalities in intracellular $\mathrm{Ca}^{2+}$ handling, with larger and prolonged $\mathrm{Ca}^{2+}$ transients. Treatment with roscovitine, a compound that increases the voltagedependent inactivation of voltage dependent $\mathrm{Ca}^{2+}$ channel, restored the electrical and calcium signaling properties of the mutant hiPSC-CMs.

Recently, Terrenoire and colleagues revealed drug actions, including sodium-channel blocker mexiletine, in a long-QT syndrome patient with complex genetics, de novo SCN5A LQT3 mutation and a polymorphism in KCNH2 (gene for LQT2) [167].

7.1.2. Catecholaminergic Polymorphic Ventricular Tachycardia (CPVT). Catecholaminergic polymorphic ventricular tachycardia (CPVT) is an arrhythmogenic disorder characterized by disturbed intracellular $\mathrm{Ca}^{2+}$ handling in the heart that, upon physical or emotional stress, leads to ventricular tachycardia, and ultimately sudden cardiac death. CPVT is mostly linked with single-point mutations in the cardiac ryanodine receptor gene (RYR2) but also in cardiac calsequestrin isoform 2 (CASQ2) gene and, even more recently identified, in triadin $(T R D N)$ [168]. Those encoding proteins regulate the intracellular $\mathrm{Ca}^{2+}$ cycling in cardiomyocytes.

Fatima et al. were the first who modelled CPVT using patient-specific iPSC-CMs with a single-point mutation in RYR2 causing arrhythmias and delayed afterdepolarizations (DADs) revealed by patch-clamp [145]. Another group reported on modelling CPVT by hiPSC-CMs and showed that application of dantrolene, a hydantoin derivative that acts as a muscle relaxant currently used as therapy for malignant hyperthermia, restored normal $\mathrm{Ca}^{2+}$ spark properties and rescued arrhythmogenic phenotype [157].

Another research suggested an important role for internal $\mathrm{Ca}^{2+}$ stores in the pathogenesis of arrhythmias in CPVT patient by using thapsigargin, a specific inhibitor of the sarcoplasmic reticulum calcium ATPase pump (SERCA) [146]. Additionally, testing of flecainide, an antiarrhytmic agent, showed that this agent possesses antiarrhythmic properties in patient-specific CPVT-iPSC-CMs suggesting a potentially new treatment for this disease. New insight into the arrhythmogenic mechanism in CPVT was provided by another research in which for the first time was reported that pa tient-specific CPVT-iPSC-CMs display early and delayed 
afterdepolarizations (EAD and DAD) which are characteristic for CPVT patients [147].

Measurements in 3D beating clusters of CPVT-hiPSCCMs showed that those clusters developed multiple $\mathrm{Ca}^{2+}$ transients when compared to wild-type clusters, indicating an arrhythmic phenotype in CPVT [148]. Arrhythmias could be exacerbated by isoproterenol ( $\beta$-adrenergic receptor agonist) and prevented by $\mathrm{KN}-93$, an antiarrhythmic drug that inhibits the calcium/calmodulin-dependent serine-threonine protein kinase II (CaMKII).

In all previously mentioned research CPVT-iPSC-CMs were generated from patients carrying mutations in RYR2 providing insights in pathophysiologic mechanisms and potential new drug treatment for this type of CPVT. Novak et al. were the first who reported modelling CPVT from the patient with mutation in CASQ2 [149].

\section{Human Pluripotent Stem Cells and Cell Replacement Therapy}

Human PSCs have the capacity to indefinite self-renewal and differentiation into all cell types in human body, including cardiomyocytes. Thus, theoretically hPSC could be unlimited source of human cardiac tissue which can be used in cell replacement therapies. Also, applying patient-specific iPSCCMs would theoretically overcome existing immunological complications connected with organ transplantation.

Cell transplantation studies on infarcted animal hearts showed that hESC-CMs survive after transplantation, partially remuscularize scar tissue forming human myocardial graft and significantly improve mechanical and electrical function of the infracted heart $[67,104,169,170]$. Transplanted hPSC-CMs electrically couple and contract synchronously with host myocardium $[169,171]$ which indicates that improvement of contractile function of infarcted hearts after cell transplantation is due to creation of new forcegenerating units in host myocardium. Also, other indirect effects of transplanted cells such as production of paracrine factors may contribute to positive effects on cardiac function of infracted hearts. These paracrine signals improve survival of host cardiomyocytes and reduce heart remodelling process after infarction [172].

Interestingly, Zwi-Dantsis et al. showed that iPSC-CMs from heart failure patients can integrate with pre-existing rat cardiac tissue and exhibit electrophysiological and pharmacological adaptation, bringing hope for cardiac regenerative medicine [26].

Since most transplantation studies were done on mice and rats, species with rapid heart rates, different cardiac physiology properties, and reaction to exercise and arrhythmogenic stimuli compared to humans, it is necessary to perform studies on large animal models with slower heart rate before clinical trials. Some of the research showed only transient beneficial effect in infracted heart after cell transplantation [170]. Therefore, it would be of interest to carry out research on long-lasting effect of transplanted hPSC-CMs in host myocardium.

\section{Summary and Outlooks}

Methods to generate patient-specific iPS-CMs have improved within the last years. Although most of the knowledge of the cardiomyogenesis using pluripotent stem cells have come from previous work achieved on ESCs, recent advances in this field make feasible a more efficient differentiation to human cardiomyocytes and a more defined resulting population of cardiac cells usable for disease modelling and drug testing in vitro. From the recent studies, it turned out that iPSCderived CMs recapitulate the phenotype of patients with inherited cardiac syndromes and pathophysiology while the maturity and purity of those cells with the time stay much more unclear. From experimental and clinical investigations, it becomes clear that the development of protocols providing specific stimuli, combining electrical, mechanical or hormonal stimulation, is required to enhance the maturity and functionality of hiPSC-CMs in order to improve those tools for drug screening, disease modelling, and potentially for cell replacement therapy.

\section{Conflict of Interests}

The authors declare no competing financial interests.

\section{Authors' Contribution}

Ivana Acimovic and Aleksandra Vilotic contributed equally to this work.

\section{Acknowledgments}

This work was supported by Grants of the Grant Agency of the Czech Republic (no. GA13-19910S), the Ministry of Education, Youth, and Sports of the Czech Republic (MSMT179/2013-311, CZ.1.07/2.3.00/20.0011, and MSM0021622430), Project FNUSA-ICRC (no. CZ.1.05/1.1.00/02.0123), European Regional Development Fund, SoMoPro and South Moravian Region, and PHC Barrande (Duchenstem no. 28379TE). The research leading to these results obtained financial contribution from the European Community within the Seventh Framework Program (FP/2007-2013) under Grant Agreement no. 229603. Dr. Albano C. Meli was supported by the European Society of Cardiology (ESC), the French Muscular Dystrophy Association (AFM, Project 16073, MNM2 2012), and by the "Fondation de la Recherche Médicale" (FRM; SPF20130526710).

\section{References}

[1] M. Nichols, N. Townsend, P. Scarborough, and M. Rayner, "European cardiovascular disease statistics 4th edition 2012: EuroHeart II," European Heart Journal, vol. 34, no. 39, Article ID 3007, 2013.

[2] R. S. Whelan, V. Kaplinskiy, and R. N. Kitsis, "Cell death in the pathogenesis of heart disease: mechanisms and significance," Annual Review of Physiology, vol. 72, pp. 19-44, 2009. 
[3] O. Bergmann, R. D. Bhardwaj, S. Bernard et al., "Evidence for cardiomyocyte renewal in humans," Science, vol. 324, no. 5923, pp. 98-102, 2009.

[4] J. Kajstura, N. Gurusamy, B. Ogórek et al., "Myocyte turnover in the aging human heart," Circulation Research, vol. 107, no. 11, pp. 1374-1386, 2010.

[5] J. Kajstura, M. Rota, D. Cappetta et al., "Cardiomyogenesis in the aging and failing human heart," Circulation, vol. 126, no. 15, pp. 1869-1881, 2012.

[6] M. Mollova, K. Bersell, S. Walsh et al., "Cardiomyocyte proliferation contributes to heart growth in young humans," Proceedings of the National Academy of Sciences of the United States of America, vol. 110, pp. 1446-1451, 2013.

[7] K. Takahashi, K. Tanabe, M. Ohnuki et al., "Induction of pluripotent stem cells from adult human fibroblasts by defined factors," Cell, vol. 131, no. 5, pp. 861-872, 2007.

[8] T. Aasen and J. C. I. Belmonte, "Isolation and cultivation of human keratinocytes from skin or plucked hair for the generation of induced pluripotent stem cells," Nature Protocols, vol. 5, no. 2, pp. 371-382, 2010.

[9] S. Ohmine, K. A. Squillace, K. A. Hartjes et al., "Reprogrammed keratinocytes from elderly type 2 diabetes patients suppress senescence genes to acquire induced pluripotency," Aging, vol. 4, no. 1, pp. 60-73, 2012.

[10] M. J. Phillips, K. A. Wallace, S. J. Dickerson et al., "Bloodderived human iPS cells generate optic vesicle-like structures with the capacity to form retinal laminae and develop synapses," Investigative Ophthalmology and Visual Science, vol. 53, pp. 2007-2019, 2012.

[11] K. Streckfuss-Bomeke, F. Wolf, A. Azizian et al., "Comparative study of human-induced pluripotent stem cells derived from bone marrow cells, hair keratinocytes, and skin fibroblasts," European Heart Journal, vol. 34, pp. 2618-2629, 2013.

[12] Y. Xue, X. Cai, L. Wang et al., "Generating a non-integrating human induced pluripotent stem cell bank from urine-derived cells," PLoS ONE, vol. 8, Article ID e70573, 2013.

[13] M. J. Evans and M. H. Kaufman, "Establishment in culture of pluripotential cells from mouse embryos," Nature, vol. 292, no. 5819, pp. 154-156, 1981.

[14] J. A. Thomson, J. Itskovitz-Eldor, S. S. Shapiro et al., "Embryonic stem cell lines derived from human blastocysts," Science, vol. 282, no. 5391, pp. 1145-1147, 1998.

[15] P. W. Andrews, "Human teratocarcinomas," Biochimica et Biophysica Acta, vol. 948, no. 1, pp. 17-36, 1988.

[16] B. Blum and N. Benvenisty, "The tumorigenicity of human embryonic stem cells," Advances in Cancer Research, vol. 100, pp. 133-158, 2008.

[17] F. Bulic-Jakus, M. Ulamec, M. Vlahovic et al., "Of mice and men: teratomas and teratocarcinomas," Collegium Antropologicum, vol. 30, pp. 921-924, 2006.

[18] I. Damjanov and P. W. Andrews, "The terminology of teratocarcinomas and teratomas," Nature Biotechnology, vol. 25, no. 11, Article ID 1212, 2007.

[19] U. Ben-David and N. Benvenisty, "The tumorigenicity of human embryonic and induced pluripotent stem cells," Nature Reviews Cancer, vol. 11, no. 4, pp. 268-277, 2011.

[20] R. Lister, M. Pelizzola, Y. S. Kida et al., "Hotspots of aberrant epigenomic reprogramming in human induced pluripotent stem cells," Nature, vol. 471, no. 7336, pp. 68-73, 2011.

[21] I. Damjanov, "Teratocarcinoma: neoplastic lessons about normal embryogenesis," International Journal of Developmental Biology, vol. 37, no. 1, pp. 39-46, 1993.
[22] J. Yu, M. A. Vodyanik, K. Smuga-Otto et al., "Induced pluripotent stem cell lines derived from human somatic cells," Science, vol. 318, no. 5858, pp. 1917-1920, 2007.

[23] M. Nakagawa, M. Koyanagi, K. Tanabe et al., "Generation of induced pluripotent stem cells without Myc from mouse and human fibroblasts," Nature Biotechnology, vol. 26, no. 1, pp. 101106, 2008.

[24] D. Huangfu, K. Osafune, R. Maehr et al., "Induction of pluripotent stem cells from primary human fibroblasts with only Oct4 and Sox2," Nature Biotechnology, vol. 26, no. 11, pp. 1269-1275, 2008.

[25] K. Woltjen, I. P. Michael, P. Mohseni et al., "PiggyBac transposition reprograms fibroblasts to induced pluripotent stem cells," Nature, vol. 458, no. 7239, pp. 766-770, 2009.

[26] I. Huber, M. Habib, A. Winterstern, A. Gepstein, G. Arbel, and L. Gepstein, "Derivation and cardiomyocyte differentiation of induced pluripotent stem cells from heart failure patients," European Heart Journal, vol. 34, no. 21, pp. 1575-1586, 2013.

[27] M. Stadtfeld, M. Nagaya, J. Utikal, G. Weir, and K. Hochedlinger, "Induced pluripotent stem cells generated without viral integration," Science, vol. 322, no. 5903, pp. 945-949, 2008.

[28] L. Warren, P. D. Manos, T. Ahfeldt et al., "Highly efficient reprogramming to pluripotency and directed differentiation of human cells with synthetic modified mRNA," Cell Stem Cell, vol. 7, no. 5, pp. 618-630, 2010.

[29] H. Zhou, S. Wu, J. Y. Joo et al., "Generation of induced pluripotent stem cells using recombinant proteins," Cell Stem Cell, vol. 4, no. 5, pp. 381-384, 2009.

[30] D. Kim, C.-H. Kim, J.-I. Moon et al., "Generation of human induced pluripotent stem cells by direct delivery of reprogramming proteins," Cell Stem Cell, vol. 4, no. 6, pp. 472-476, 2009.

[31] J. Lee, N. Sayed, A. Hunter et al., "Activation of innate immunity is required for efficient nuclear reprogramming," Cell, vol. 151, pp. 547-558, 2012.

[32] C. Mummery, D. Ward-Van Oostwaard, P. Doevendans et al., "Differentiation of human embryonic stem cells to cardiomyocytes: role of coculture with visceral endoderm-like cells," Circulation, vol. 107, no. 21, pp. 2733-2740, 2003.

[33] R. Passier, D. Ward-Van Oostwaard, J. Snapper et al., "Increased cardiomyocyte differentiation from human embryonic stem cells in serum-free cultures," Stem Cells, vol. 23, no. 6, pp. 772780, 2005.

[34] C. Freund, R. P. Davis, K. Gkatzis, D. Ward-Van Oostwaard, and C. L. Mummery, "The first reported generation of human induced pluripotent stem cells (iPS cells) and iPS cell-derived cardiomyocytes in the Netherlands," Netherlands Heart Journal, vol. 18, no. 1, pp. 51-54, 2010.

[35] A. B. McLean, K. A. D’Amour, K. L. Jones et al., "Activin A efficiently specifies definitive endoderm from human embryonic stem cells only when phosphatidylinositol 3-kinase signaling is suppressed," Stem Cells, vol. 25, no. 1, pp. 29-38, 2007.

[36] C. Freund, D. Ward-Van Oostwaard, J. Monshouwer-Kloots et al., "Insulin redirects differentiation from cardiogenic mesoderm and endoderm to neuroectoderm in differentiating human embryonic stem cells," Stem Cells, vol. 26, no. 3, pp. 724733, 2008.

[37] T. Takahashi, B. Lord, P. C. Schulze et al., "Ascorbic acid enhances differentiation of embryonic stem cells into cardiac myocytes," Circulation, vol. 107, no. 14, pp. 1912-1916, 2003.

[38] N. Cao, Z. Liu, Z. Chen et al., "Ascorbic acid enhances the cardiac differentiation of induced pluripotent stem cells through 
promoting the proliferation of cardiac progenitor cells," Cell Research, vol. 22, no. 1, pp. 219-236, 2012.

[39] I. Kehat, D. Kenyagin-Karsenti, M. Snir et al., "Human embryonic stem cells can differentiate into myocytes with structural and functional properties of cardiomyocytes," Journal of Clinical Investigation, vol. 108, no. 3, pp. 407-414, 2001.

[40] S. Takei, H. Ichikawa, K. Johkura et al., "Bone morphogenetic protein-4 promotes induction of cardiomyocytes from human embryonic stem cells in serum-based embryoid body development," The American Journal of Physiology, vol. 296, no. 6, pp. H1793-H1803, 2009.

[41] E. Bettiol, L. Sartiani, L. Chicha, K. H. Krause, E. Cerbai, and M. E. Jaconi, "Fetal bovine serum enables cardiac differentiation of human embryonic stem cells," Differentiation, vol. 75, no. 8, pp. 669-681, 2007.

[42] C. Xu, S. Police, N. Rao, and M. K. Carpenter, "Characterization and enrichment of cardiomyocytes derived from human embryonic stem cells," Circulation Research, vol. 91, no. 6, pp. 501-508, 2002.

[43] C. Xu, J.-Q. He, T. J. Kamp et al., "Human embryonic stem cellderived cardiomyocytes can be maintained in defined medium without serum," Stem Cells and Development, vol. 15, no. 6, pp. 931-941, 2006.

[44] W. Dai, L. J. Field, M. Rubart et al., "Survival and maturation of human embryonic stem cell-derived cardiomyocytes in rat hearts," Journal of Molecular and Cellular Cardiology, vol. 43, no. 4, pp. 504-516, 2007.

[45] X. Q. Xu, R. Graichen, S. Y. Soo et al., "Chemically defined medium supporting cardiomyocyte differentiation of human embryonic stem cells," Differentiation, vol. 76, no. 9, pp. 958970, 2008.

[46] R. Graichen, X. Xu, S. R. Braam et al., "Enhanced cardiomyogenesis of human embryonic stem cells by a small molecular inhibitor of p38 MAPK," Differentiation, vol. 76, no. 4, pp. 357$370,2008$.

[47] P. Zhang, J. Li, Z. Tan et al., "Short-term BMP-4 treatment initiates mesoderm induction in human embryonic stem cells," Blood, vol. 111, no. 4, pp. 1933-1941, 2008.

[48] R.-H. Xu, X. Chen, D. S. Li et al., "BMP4 initiates human embryonic stem cell differentiation to trophoblast," Nature Biotechnology, vol. 20, no. 12, pp. 1261-1264, 2002.

[49] B. J. Conley, S. Ellis, L. Gulluyan, and R. Mollard, "BMPs regulate differentiation of a putative visceral endoderm layer within human embryonic stem-cell-derived embryoid bodies," Biochemistry and Cell Biology, vol. 85, no. 1, pp. 121-132, 2007.

[50] X. Lian, C. Hsiao, G. Wilson et al., "Robust cardiomyocyte differentiation from human pluripotent stem cells via temporal modulation of canonical Wnt signaling," Proceedings of the National Academy of Sciences of the United States of America, vol. 109, pp. E1848-E1857, 2012.

[51] T. H. Tran, X. Wang, C. Browne et al., "Wnt3a-induced mesoderm formation and cardiomyogenesis in human embryonic stem cells," Stem Cells, vol. 27, no. 8, pp. 1869-1878, 2009.

[52] I. Minami, K. Yamada, T. G. Otsuji et al., "A small molecule that promotes cardiac differentiation of human pluripotent stem cells under defined, cytokine- and xeno-free conditions," Cell Reports, vol. 2, pp. 1448-1460, 2012.

[53] Y. Ren, M. Y. Lee, S. Schliffke et al., "Small molecule Wnt inhibitors enhance the efficiency of BMP-4-directed cardiac differentiation of human pluripotent stem cells," Journal of Molecular and Cellular Cardiology, vol. 51, no. 3, pp. 280-287, 2011.
[54] E. Willems, S. Spiering, H. Davidovics et al., "Small-molecule inhibitors of the Wnt pathway potently promote cardiomyocytes from human embryonic stem cell-derived mesoderm," Circulation Research, vol. 109, no. 4, pp. 360-364, 2011.

[55] L. Yang, M. H. Soonpaa, E. D. Adler et al., "Human cardiovascular progenitor cells develop from a KDR+ embryonic-stemcell-derived population," Nature, vol. 453, no. 7194, pp. 524-528, 2008.

[56] S. J. Kattman, A. D. Witty, M. Gagliardi et al., "Stage-specific optimization of activin/nodal and BMP signaling promotes cardiac differentiation of mouse and human pluripotent stem cell lines," Cell Stem Cell, vol. 8, no. 2, pp. 228-240, 2011.

[57] M. Pesl, I. Acimovic, J. Pribyl et al., "Forced aggregation and defined factors allow highly uniform-sized embryoid bodies and functional cardiomyocytes from human embryonic and induced pluripotent stem cells," Heart and Vessels, 2013.

[58] S. Y. Lim, P. Sivakumaran, D. E. Crombie, G. J. Dusting, A. Pebay, and R. J. Dilley, "Trichostatin A enhances differentiation of human induced pluripotent stem cells to cardiogenic cells for cardiac tissue engineering," Stem Cells Translational Medicine, vol. 2, pp. 715-725, 2013.

[59] A. Bader, A. Gruss, A. Höllrigl, H. Al-Dubai, Y. Capetanaki, and G. Weitzer, "Paracrine promotion of cardiomyogenesis in embryoid bodies by LIF modulated endoderm," Differentiation, vol. 68, no. 1, pp. 31-43, 2001.

[60] M. Y. Lee, E. Cagavi Bozkulak, S. Schliffke et al., "High density cultures of embryoid bodies enhanced cardiac differentiation of murine embryonic stem cells," Biochemical and Biophysical Research Communications, vol. 416, no. 1-2, pp. 51-57, 2011.

[61] C. L. Bauwens, R. Peerani, S. Niebruegge et al., "Control of human embryonic stem cell colony and aggregate size heterogeneity influences differentiation trajectories," Stem Cells, vol. 26, no. 9, pp. 2300-2310, 2008.

[62] M. D. Ungrin, C. Joshi, A. Nica, C. Bauwens, and P. W. Zandstra, "Reproducible, ultra high-throughput formation of multicellular organization from single cell suspension-derived human embryonic stem cell aggregates," PLOS ONE, vol. 3, no. 2, Article ID e1565, 2008

[63] K. Watanabe, M. Ueno, D. Kamiya et al., "A ROCK inhibitor permits survival of dissociated human embryonic stem cells," Nature Biotechnology, vol. 25, no. 6, pp. 681-686, 2007.

[64] E. S. Ng, R. P. Davis, L. Azzola, E. G. Stanley, and A. G. Elefanty, "Forced aggregation of defined numbers of human embryonic stem cells into embryoid bodies fosters robust, reproducible hematopoietic differentiation," Blood, vol. 106, no. 5, pp. 16011603, 2005.

[65] P. W. Burridge, D. Anderson, H. Priddle et al., "Improved human embryonic stem cell embryoid body homogeneity and cardiomyocyte differentiation from a novel V-96 plate aggregation system highlights interline variability," Stem Cells, vol. 25, no. 4, pp. 929-938, 2007.

[66] P. W. Burridge, S. Thompson, M. A. Millrod et al., "A universal system for highly efficient cardiac differentiation of human induced pluripotent stem cells that eliminates interline variability," PLoS ONE, vol. 6, no. 4, Article ID e18293, 2011.

[67] M. A. Laflamme, K. Y. Chen, A. V. Naumova et al., "Cardiomyocytes derived from human embryonic stem cells in prosurvival factors enhance function of infarcted rat hearts," Nature Biotechnology, vol. 25, no. 9, pp. 1015-1024, 2007. 
[68] Z. Melkoumian, J. L. Weber, D. M. Weber et al., "Synthetic peptide-acrylate surfaces for long-term self-renewal and cardiomyocyte differentiation of human embryonic stem cells," Nature Biotechnology, vol. 28, no. 6, pp. 606-610, 2010.

[69] S. L. Paige, T. Osugi, O. K. Afanasiev, L. Pabon, H. Reinecke, and C. E. Murry, "Endogenous Wnt/beta-catenin signaling is required for cardiac differentiation in human embryonic stem cells," PLoS ONE, vol. 5, no. 6, Article ID el1134, 2010.

[70] J. Hudson, D. Titmarsh, A. Hidalgo, E. Wolvetang, and J. Cooper-White, "Primitive cardiac cells from human embryonic stem cells," Stem Cells and Development, vol. 21, no. 9, pp. 15131523, 2012.

[71] Q. Zhang, J. Jiang, P. Han et al., "Direct differentiation of atrial and ventricular myocytes from human embryonic stem cells by alternating retinoid signals," Cell Research, vol. 21, no. 4, pp. 579-587, 2011.

[72] H. Uosaki, H. Fukushima, A. Takeuchi et al., "Efficient and scalable purification of cardiomyocytes from human embryonic and induced pluripotent stem cells by VCAM1 surface expression," PLoS ONE, vol. 6, Article ID e23657, 2011.

[73] J. Zhang, M. Klos, G. F. Wilson et al., "Extracellular matrix promotes highly efficient cardiac differentiation of human pluripotent stem cells: the matrix sandwich method," Circulation Research, vol. 111, pp. 1125-1136, 2012.

[74] X. Lian, J. Zhang, S. M. Azarin et al., "Directed cardiomyocyte differentiation from human pluripotent stem cells by modulating Wnt/beta-catenin signaling under fully defined conditions," Nature Protocols, vol. 8, pp. 162-175, 2013.

[75] X. Lian, J. Zhang, K. Zhu, T. J. Kamp, and S. P. Palecek, "Insulin inhibits cardiac mesoderm, not mesendoderm, formation during cardiac differentiation of human pluripotent stem cells and modulation of canonical Wnt signaling can rescue this inhibition," Stem Cells, vol. 31, pp. 447-457, 2013.

[76] D. Steiner, H. Khaner, M. Cohen et al., "Derivation, propagation and controlled differentiation of human embryonic stem cells in suspension," Nature Biotechnology, vol. 28, no. 4, pp. 361-364, 2010.

[77] H. Singh, P. Mok, T. Balakrishnan, S. N. B. Rahmat, and R. Zweigerdt, "Up-scaling single cell-inoculated suspension culture of human embryonic stem cells," Stem Cell Research, vol. 4, no. 3, pp. 165-179, 2010.

[78] R. Olmer, A. Haase, S. Merkert et al., "Long term expansion of undifferentiated human iPS and ES cells in suspension culture using a defined medium," Stem Cell Research, vol. 5, no. 1, pp. 51-64, 2010.

[79] R. Zweigerdt, R. Olmer, H. Singh, A. Haverich, and U. Martin, "Scalable expansion of human pluripotent stem cells in suspension culture," Nature Protocols, vol. 6, no. 5, pp. 689-700, 2011.

[80] R. Krawetz, J. T. Taiani, S. Liu et al., "Large-scale expansion of pluripotent human embryonic stem cells in stirred-suspension bioreactors," Tissue Engineering C, vol. 16, no. 4, pp. 573-582, 2010.

[81] R. Olmer, A. Lange, S. Selzer et al., "Suspension culture of human pluripotent stem cells in controlled, stirred bioreactors," Tissue Engineering C, vol. 18, pp. 772-784, 2012.

[82] M. Shafa, K. Sjonnesen, A. Yamashita et al., "Expansion and long-term maintenance of induced pluripotent stem cells in stirred suspension bioreactors," Journal of Tissue Engineering and Regenerative Medicine, vol. 6, pp. 462-472, 2012.

[83] S. Abbasalizadeh, M. R. Larijani, A. Samadian, and H. Baharvand, "Bioprocess development for mass production of sizecontrolled human pluripotent stem cell aggregates in stirred suspension bioreactor," Tissue Engineering C, vol. 18, pp. 831851, 2012.

[84] C. Bauwens, T. Yin, S. Dang, R. Peerani, and P. W. Zandstra, "Development of a perfusion fed bioreactor for embryonic stem cell-derived cardiomyocyte generation: oxygen-mediated enhancement of cardiomyocyte output," Biotechnology and Bioengineering, vol. 90, no. 4, pp. 452-461, 2005.

[85] M. Schroeder, S. Niebruegge, A. Werner et al., "Differentiation and lineage selection of mouse embryonic stem cells in a stirred bench scale bioreactor with automated process control," Biotechnology and Bioengineering, vol. 92, no. 7, pp. 920-933, 2005.

[86] S. Niebruegge, C. L. Bauwens, R. Peerani et al., "Generation of human embryonic stem cell-derived mesoderm and cardiac cells using size-specified aggregates in an oxygen-controlled bioreactor," Biotechnology and Bioengineering, vol. 102, no. 2, pp. 493-507, 2009.

[87] D. Jing, A. Parikh, and E. S. Tzanakakis, "Cardiac cell generation from encapsulated embryonic stem cells in static and scalable culture systems," Cell Transplantation, vol. 19, no. 11, pp. 1397$1412,2010$.

[88] G. Yirme, M. Amit, I. Laevsky, S. Osenberg, and J. ItskovitzEldor, "Establishing a dynamic process for the formation, propagation, and differentiation of human embryoid bodies," Stem Cells and Development, vol. 17, no. 6, pp. 1227-1241, 2008.

[89] G. Vunjak-Novakovic and D. T. Scadden, "Biomimetic platforms for human stem cell research," Cell Stem Cell, vol. 8, no. 3, pp. 252-261, 2011.

[90] S. Schaaf, A. Shibamiya, M. Mewe et al., "Human engineered heart tissue as a versatile tool in basic research and preclinical toxicology," PLoS ONE, vol. 6, no. 10, Article ID e26397, 2011.

[91] W.-H. Zimmermann, I. Melnychenko, G. Wasmeier et al., "Engineered heart tissue grafts improve systolic and diastolic function in infarcted rat hearts," Nature Medicine, vol. 12, no. 4, pp. 452-458, 2006.

[92] A. Furuta, S. Miyoshi, Y. Itabashi et al., "Pulsatile cardiac tissue grafts using a novel three-dimensional cell sheet manipulation technique functionally integrates with the host heart, in vivo," Circulation Research, vol. 98, no. 5, pp. 705-712, 2006.

[93] T. Shimizu, M. Yamato, Y. Isoi et al., "Fabrication of pulsatile cardiac tissue grafts using a novel 3-dimensional cell sheet manipulation technique and temperature-responsive cell culture surfaces," Circulation Research, vol. 90, no. 3, article e40, 2002.

[94] A. Bel, V. Planat-Bernard, A. Saito et al., "Composite cell sheets: a further step toward safe and effective myocardial regeneration by cardiac progenitors derived from embryonic stem cells," Circulation, vol. 122, no. 11, pp. S118-S123, 2010.

[95] W.-H. Zimmermann, K. Schneiderbanger, P. Schubert et al., "Tissue engineering of a differentiated cardiac muscle construct," Circulation Research, vol. 90, no. 2, pp. 223-230, 2002.

[96] M. Radisic, W. Deen, R. Langer, and G. Vunjak-Novakovic, "Mathematical model of oxygen distribution in engineered cardiac tissue with parallel channel array perfused with culture medium containing oxygen carriers," The American Journal of Physiology, vol. 288, no. 3, pp. H1278-H1289, 2005.

[97] M. Radisic, J. Malda, E. Epping, W. Geng, R. Langer, and G. Vunjak-Novakovic, "Oxygen gradients correlate with cell density and cell viability in engineered cardiac tissue," Biotechnology and Bioengineering, vol. 93, no. 2, pp. 332-343, 2006. 
[98] M. Radisic, H. Park, F. Chen et al., "Biomimetic approach to cardiac tissue engineering: oxygen carriers and channeled scaffolds," Tissue Engineering, vol. 12, no. 8, pp. 2077-2091, 2006.

[99] M. Radisic, H. Park, H. Shing et al., "Functional assembly of engineered myocardium by electrical stimulation of cardiac myocytes cultured on scaffolds," Proceedings of the National Academy of Sciences of the United States of America, vol. 101, no. 52, pp. 18129-18134, 2004.

[100] N. Tandon, C. Cannizzaro, P.-H. G. Chao et al., "Electrical stimulation systems for cardiac tissue engineering," Nature Protocols, vol. 4, no. 2, pp. 155-173, 2009.

[101] L. L. Y. Chiu, R. K. Iyer, J.-P. King, and M. Radisic, "Biphasic electrical field stimulation aids in tissue engineering of multicell-type cardiac organoids," Tissue Engineering A, vol. 17, no. 11-12, pp. 1465-1475, 2011.

[102] T. Y. Lu, B. Lin, J. Kim et al., "Repopulation of decellularized mouse heart with human induced pluripotent stem cell-derived cardiovascular progenitor cells," Nature Communications, vol. 4, Article ID 2307, 2013.

[103] H. C. Ott, T. S. Matthiesen, S.-K. Goh et al., "Perfusiondecellularized matrix: using nature's platform to engineer a bioartificial heart," Nature Medicine, vol. 14, no. 2, pp. 213-221, 2008.

[104] O. Caspi, A. Lesman, Y. Basevitch et al., "Tissue engineering of vascularized cardiac muscle from human embryonic stem cells," Circulation Research, vol. 100, no. 2, pp. 263-272, 2007.

[105] K. R. Stevens, L. Pabon, V. Muskheli, and C. E. Murry, "Scaffoldfree human cardiac tissue patch created from embryonic stem cells," Tissue Engineering A, vol. 15, no. 6, pp. 1211-1222, 2009.

[106] A. Lesman, M. Habib, O. Caspi et al., "Transplantation of a tissue-engineered human vascularized cardiac muscle," Tissue Engineering A, vol. 16, no. 1, pp. 115-125, 2010.

[107] B. Liau, N. Christoforou, K. W. Leong, and N. Bursac, "Pluripotent stem cell-derived cardiac tissue patch with advanced structure and function," Biomaterials, vol. 32 , no. 35 , pp. 91809187, 2011.

[108] K. Matsuura, S. Masuda, Y. Haraguchi et al., "Creation of mouse embryonic stem cell-derived cardiac cell sheets," Biomaterials, vol. 32, no. 30, pp. 7355-7362, 2011.

[109] J. Satin, I. Itzhaki, S. Rapoport et al., "Calcium handling in human embryonic stem cell-derived cardiomyocytes," Stem Cells, vol. 26, no. 8, pp. 1961-1972, 2008.

[110] I. Itzhaki, S. Rapoport, I. Huber et al., "Calcium handling in human induced pluripotent stem cell derived cardiomyocytes," PLoS ONE, vol. 6, no. 4, Article ID e18037, 2011.

[111] D. Zhang, I. Y. Shadrin, J. Lam, H. Q. Xian, H. R. Snodgrass, and N. Bursac, "Tissue-engineered cardiac patch for advanced functional maturation of human ESC-derived cardiomyocytes," Biomaterials, vol. 34, pp. 5813-5820, 2013.

[112] R. L. Davis, H. Weintraub, and A. B. Lassar, "Expression of a single transfected cDNA converts fibroblasts to myoblasts," Cell, vol. 51, no. 6, pp. 987-1000, 1987.

[113] R. Ambasudhan, M. Talantova, R. Coleman et al., "Direct reprogramming of adult human fibroblasts to functional neurons under defined conditions," Cell Stem Cell, vol. 9, no. 2, pp. 113118, 2011.

[114] M. Caiazzo, M. T. Dell'Anno, E. Dvoretskova et al., "Direct generation of functional dopaminergic neurons from mouse and human fibroblasts," Nature, vol. 476, no. 7359, pp. 224-227, 2011.
[115] E. Y. Son, J. K. Ichida, B. J. Wainger et al., "Conversion of mouse and human fibroblasts into functional spinal motor neurons," Cell Stem Cell, vol. 9, no. 3, pp. 205-218, 2011.

[116] P. Huang, Z. He, S. Ji et al., "Induction of functional hepatocytelike cells from mouse fibroblasts by defined factors," Nature, vol. 475, no. 7356, pp. 386-391, 2011.

[117] S. Sekiya and A. Suzuki, "Direct conversion of mouse fibroblasts to hepatocyte-like cells by defined factors," Nature, vol. 475, no. 7356, pp. 390-395, 2011.

[118] M. Ieda, J.-D. Fu, P. Delgado-Olguin et al., "Direct reprogramming of fibroblasts into functional cardiomyocytes by defined factors," Cell, vol. 142, no. 3, pp. 375-386, 2010.

[119] J. D. Fu, N. R. Stone, L. Liu et al., "Direct reprogramming of human fibroblasts toward a cardiomyocyte-like state," Stem Cell Reports, vol. 1, pp. 235-247, 2013.

[120] R. Wada, N. Muraoka, K. Inagawa et al., "Induction of human cardiomyocyte-like cells from fibroblasts by defined factors," Proceedings of the National Academy of Sciences of the United States of America, vol. 110, pp. 12667-12672, 2013.

[121] K. Inagawa, K. Miyamoto, H. Yamakawa et al., "Induction of cardiomyocyte-like cells in infarct hearts by gene transfer of Gata4, Mef2c, and Tbx5," Circulation Research, vol. 111, pp. 11471156, 2012.

[122] K. Song, Y. J. Nam, X. Luo et al., "Heart repair by reprogramming non-myocytes with cardiac transcription factors," Nature, vol. 485, pp. 599-604, 2012.

[123] L. Qian, Y. Huang, C. I. Spencer et al., "In vivo reprogramming of murine cardiac fibroblasts into induced cardiomyocytes," Nature, vol. 485, pp. 593-598, 2012.

[124] P. Anversa and J. Kajstura, "Ventricular myocytes are not terminally differentiated in the adult mammalian heart," Circulation Research, vol. 83, no. 1, pp. 1-14, 1998.

[125] A. P. Beltrami, K. Urbanek, J. Kajstura et al., "Evidence that human cardiac myocytes divide after myocardial infarction," The New England Journal of Medicine, vol. 344, no. 23, pp. 17501757, 2001.

[126] O. Bergmann, S. Zdunek, J. Frisén, S. Bernard, H. Druid, and S. Jovinge, "Cardiomyocyte renewal in humans," Circulation Research, vol. 110, no. 1, pp. e17-e18, 2012.

[127] C. Y. Ivashchenko, G. C. Pipes, I. M. Lozinskaya et al., "Humaninduced pluripotent stem cell-derived cardiomyocytes exhibit temporal changes in phenotype," The American Journal of Physiology, vol. 305, pp. H913-H922, 2013.

[128] Y.-K. Lee, K.-M. Ng, W.-H. Lai et al., "Calcium homeostasis in human induced pluripotent stem cell-derived cardiomyocytes," Stem Cell Reviews and Reports, vol. 7, no. 4, pp. 976-986, 2011.

[129] S. D. Lundy, W. Z. Zhu, M. Regnier, and M. A. Laflamme, "Structural and functional maturation of cardiomyocytes derived from human pluripotent stem cells," Stem Cells and Development, vol. 22, pp. 1991-2002, 2013.

[130] A. F. M. Moorman, F. de Jong, M. M. F. J. Denyn, and W. H. Lamers, "Development of the cardiac conduction system," Circulation Research, vol. 82, no. 6, pp. 629-644, 1998.

[131] C.-L. Cai, X. Liang, Y. Shi et al., "Isl1 identifies a cardiac progenitor population that proliferates prior to differentiation and contributes a majority of cells to the heart," Developmental Cell, vol. 5, no. 6, pp. 877-889, 2003.

[132] L. Chen, F. G. Fulcoli, S. Tang, and A. Baldini, "Tbx1 regulates proliferation and differentiation of multipotent heart progenitors," Circulation Research, vol. 105, no. 9, pp. 842-851, 2009. 
[133] G. Blin, D. Nury, S. Stefanovic et al., "A purified population of multipotent cardiovascular progenitors derived from primate pluripotent stem cells engrafts in postmyocardial infarcted nonhuman primates," Journal of Clinical Investigation, vol. 120, no. 4, pp. 1125-1139, 2010.

[134] E. G. Stanley, C. Biben, A. Elefanty et al., "Efficient cre-mediated deletion in cardiac progenitor cells conferred by a 3/UTR-iresCre allele of the homeobox gene Nkx2-5," International Journal of Developmental Biology, vol. 46, no. 4, pp. 431-439, 2002.

[135] S. S. Nunes, J. W. Miklas, J. Liu et al., "Biowire: a platform for maturation of human pluripotent stem cell-derived cardiomyocytes," Nature Methods, vol. 10, pp. 781-787, 2013.

[136] N. L. Tulloch, V. Muskheli, M. V. Razumova et al., "Growth of engineered human myocardium with mechanical loading and vascular coculture," Circulation Research, vol. 109, no. 1, pp. 4759, 2011.

[137] X. Carvajal-Vergara, A. Sevilla, S. L. Dsouza et al., "Patientspecific induced pluripotent stem-cell-derived models of LEOPARD syndrome," Nature, vol. 465, no. 7299, pp. 808-812, 2010.

[138] A. Moretti, M. Bellin, A. Welling et al., "Patient-specific induced pluripotent stem-cell models for long-QT syndrome," The New England Journal of Medicine, vol.363, no. 15, pp. 1397-1409, 2010.

[139] T. Egashira, S. Yuasa, T. Suzuki et al., "Disease characterization using LQTS-specific induced pluripotent stem cells," Cardiovascular Research, vol. 95, pp. 419-429, 2012.

[140] I. Itzhaki, L. Maizels, I. Huber et al., "Modelling the long QT syndrome with induced pluripotent stem cells," Nature, vol. 471, no. 7337, pp. 225-230, 2011.

[141] E. Matsa, D. Rajamohan, E. Dick et al., "Drug evaluation in cardiomyocytes derived from human induced pluripotent stem cells carrying a long QT syndrome type 2 mutation," European Heart Journal, vol. 32, no. 8, pp. 952-962, 2011.

[142] A. L. Lahti, V. J. Kujala, H. Chapman et al., "Model for long QT syndrome type 2 using human iPS cells demonstrates arrhythmogenic characteristics in cell culture," DMM Disease Models and Mechanisms, vol. 5, no. 2, pp. 220-230, 2012.

[143] R. P. Davis, S. Casini, C. W. van den Berg et al., "Cardiomyocytes derived from pluripotent stem cells recapitulate electrophysiological characteristics of an overlap syndrome of cardiac sodium channel disease," Circulation, vol. 125, pp. 3079-3091, 2012.

[144] M. Yazawa, B. Hsueh, X. Jia et al., "Using induced pluripotent stem cells to investigate cardiac phenotypes in Timothy syndrome," Nature, vol. 471, no. 7337, pp. 230-236, 2011.

[145] A. Fatima, G. Xu, K. Shao et al., "In vitro modeling of ryanodine receptor 2 dysfunction using human induced pluripotent stem cells," Cellular Physiology and Biochemistry, vol. 28, no. 4, pp. 579-592, 2011.

[146] I. Itzhaki, L. Maizels, I. Huber et al., "Modeling of catecholaminergic polymorphic ventricular tachycardia with patient-specific human-induced pluripotent stem cells," Journal of the American College of Cardiology, vol. 60, pp. 990-1000, 2012.

[147] K. Kujala, J. Paavola, A. Lahti et al., "Cell model of catecholaminergic polymorphic ventricular tachycardia reveals early and delayed afterdepolarizations," PLOS ONE, vol. 7, Article ID e44660, 2012.

[148] E. Di Pasquale, F. Lodola, M. Miragoli et al., "CaMKII inhibition rectifies arrhythmic phenotype in a patient-specific model of catecholaminergic polymorphic ventricular tachycardia," Cell Death and Disease, vol. 4, Article ID e843, 2013.
[149] A. Novak, L. Barad, N. Zeevi-Levin et al., "Cardiomyocytes generated from CPVTD307H patients are arrhythmogenic in response to $\beta$-adrenergic stimulation," Journal of Cellular and Molecular Medicine, vol. 16, no. 3, pp. 468-482, 2012.

[150] N. Sun, M. Yazawa, J. Liu et al., "Patient-specific induced pluripotent stem cells as a model for familial dilated cardiomyopathy," Science Translational Medicine, vol. 4, no. 130, Article ID 130ra47, 2012.

[151] D. Ma, H. Wei, J. Lu et al., "Generation of patient-specific induced pluripotent stem cell-derived cardiomyocytes as a cellular model of arrhythmogenic right ventricular cardiomyopathy," European Heart Journal, vol. 34, pp. 1122-1133, 2012.

[152] F. Kamdar, M. J. Doyle, C. Chapman, J. Lohr, N. Koyano Nakagawa, and D. J. Garry, "In vitro modeling of duchenne muscular dystrophy (DMD) cardiomyopathy using human induced pluripotent stem cells (hiPSC)," The Journal of Heart and Lung Transplantation, vol. 32, no. 4, p. S245, 2013.

[153] C. Kim, J. Wong, J. Wen et al., "Studying arrhythmogenic right ventricular dysplasia with patient-specific iPSCs," Nature, vol. 494, pp. 105-110, 2013.

[154] S. Okata, S. Yuasa, T. Yamane, T. Furukawa, and K. Fukuda, "The generation of induced pluripotent stem cells from a patient with KCNH2 G603D, without LQT2 disease associated symptom," Journal of Medical and Dental Sciences, vol. 60, pp. 17-22, 2013.

[155] E. Matsa, J. E. Dixon, C. Medway et al., "Allele-specific RNA interference rescues the long-QT syndrome phenotype in human-induced pluripotency stem cell cardiomyocytes," European Heart Journal, 2013.

[156] D. Ma, H. Wei, Y. Zhao et al., "Modeling type 3 long QT syndrome with cardiomyocytes derived from patient-specific induced pluripotent stem cells," International Journal of Cardiology, vol. 168, pp. 5277-5286, 2013.

[157] C. B. Jung, A. Moretti, M. Mederos y Schnitzler et al., "Dantrolene rescues arrhythmogenic RYR2 defect in a patient-specific stem cell model of catecholaminergic polymorphic ventricular tachycardia," EMBO Molecular Medicine, vol. 4, no. 3, pp. 180191, 2012.

[158] X. H. Zhang, S. Haviland, H. Wei et al., "Ca2+ signaling in human induced pluripotent stem cell-derived cardiomyocytes (iPS-CM) from normal and catecholaminergic polymorphic ventricular tachycardia (CPVT)-afflicted subjects," Cell Calcium, vol. 54, no. 2, pp. 57-70, 2013.

[159] F. Lan, A. S. Lee, P. Liang et al., "Abnormal calcium handling properties underlie familial hypertrophic cardiomyopathy pathology in patient-specific induced pluripotent stem cells," Cell Stem Cell, vol. 12, pp. 101-113, 2013.

[160] M. Bellin, S. Casini, R. P. Davis et al., "Isogenic human pluripotent stem cell pairs reveal the role of a $\mathrm{KCNH} 2$ mutation in long-QT syndrome," The EMBO Journal, vol. 32, pp. 31613175, 2013.

[161] L.-T. Cheng, L.-T. Sun, and T. Tada, "Genome editing in induced pluripotent stem cells," Genes to Cells, 2012.

[162] D. G. Ousterout, P. Perez-Pinera, P. I. Thakore et al., "Reading frame correction by targeted genome editing restores dystrophin expression in cells from Duchenne muscular dystrophy patients," Molecular Therapy Advance, 2013.

[163] F. Soldner, J. Laganière, A. W. Cheng et al., "Generation of isogenic pluripotent stem cells differing exclusively at two early onset parkinson point mutations," Cell, vol. 146, pp. 318-331, 2011. 
[164] K. Kim, A. Doi, B. Wen et al., "Epigenetic memory in induced pluripotent stem cells," Nature, vol. 467, no. 7313, pp. 285-290, 2010.

[165] P. J. Schwartz, M. Stramba-Badiale, L. Crotti et al., "Prevalence of the congenital long-qt syndrome," Circulation, vol. 120, no. 18, pp. 1761-1767, 2009.

[166] N. J. Bokil, J. M. Baisden, D. J. Radford, and K. M. Summers, "Molecular genetics of long QT syndrome," Molecular Genetics and Metabolism, vol. 101, no. 1, pp. 1-8, 2010.

[167] C. Terrenoire, K. Wang, K. W. Tung et al., "Induced pluripotent stem cells used to reveal drug actions in a long QT syndrome family with complex genetics," Journal of General Physiology, vol. 141, pp. 61-72, 2013.

[168] N. Roux-Buisson, M. Cacheux, A. Fourest-Lieuvin et al., "Absence of triadin, a protein of the calcium release complex, is responsible for cardiac arrhythmia with sudden death in human," Human Molecular Genetics, vol. 21, pp. 2759-2767, 2012.

[169] Y. Shiba, S. Fernandes, W. Z. Zhu et al., "Human ES-cell-derived cardiomyocytes electrically couple and suppress arrhythmias in injured hearts," Nature, vol. 489, pp. 322-325, 2012.

[170] L. W. Van Laake, R. Passier, P. A. Doevendans, and C. L. Mummery, "Human embryonic stem cell-derived cardiomyocytes and cardiac repair in rodents," Circulation Research, vol. 102, no. 9, pp. 1008-1010, 2008.

[171] I. Kehat, L. Khimovich, O. Caspi et al., "Electromechanical integration of cardiomyocytes derived from human embryonic stem cells," Nature Biotechnology, vol. 22, no. 10, pp. 1282-1289, 2004.

[172] H. Ebelt, M. Jungblut, Y. Zhang et al., "Cellular cardiomyoplasty: improvement of left ventricular function correlates with the release of cardioactive cytokines," Stem Cells, vol. 25, no. 1, pp. 236-244, 2007. 


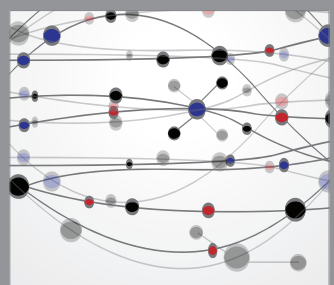

The Scientific World Journal
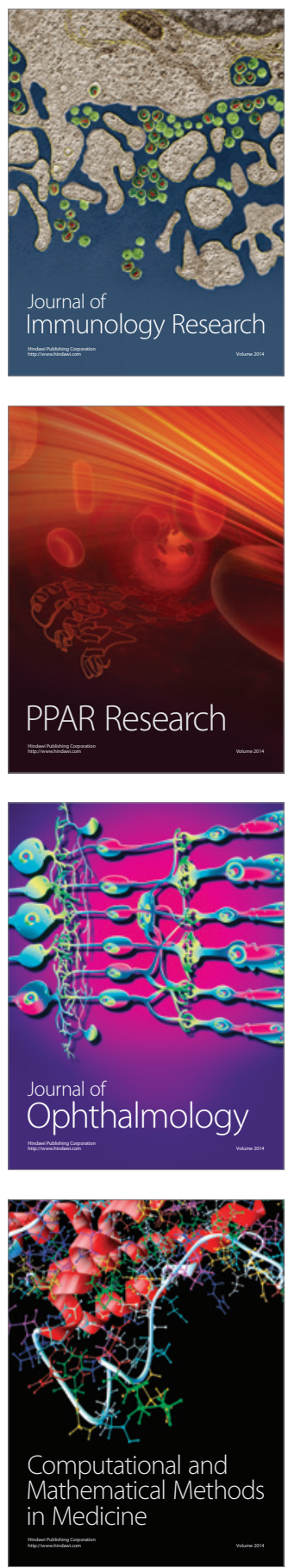

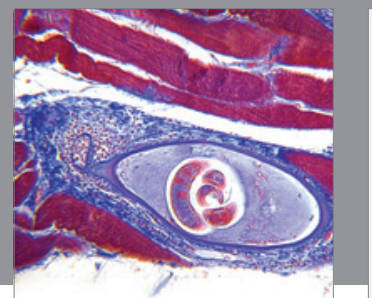

Gastroenterology

Research and Practice
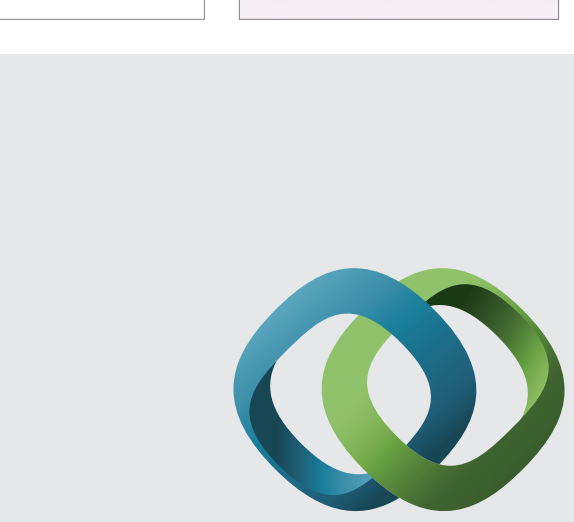

\section{Hindawi}

Submit your manuscripts at

http://www.hindawi.com
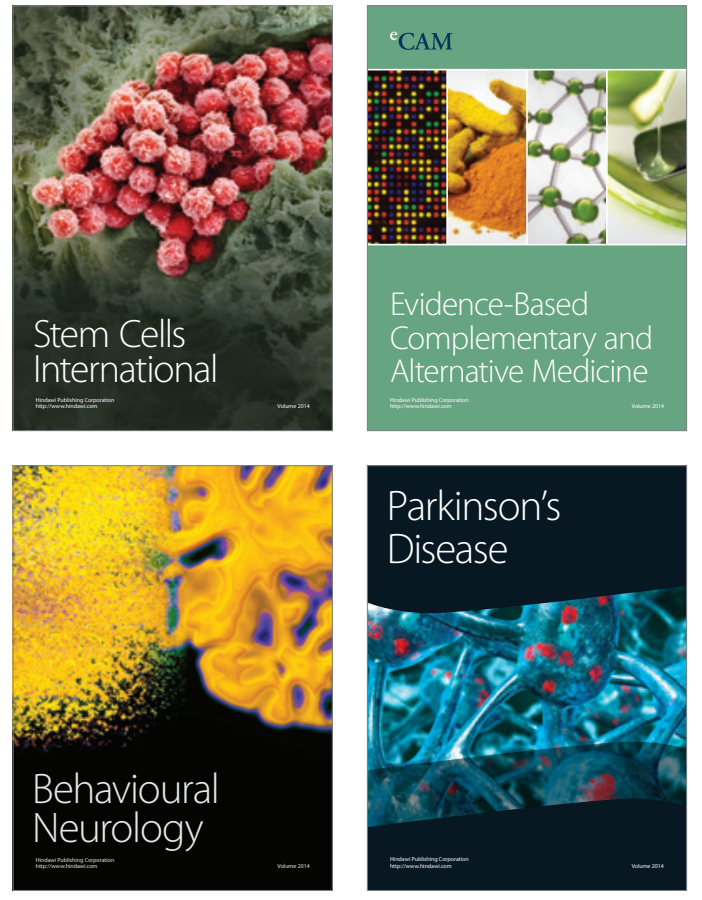
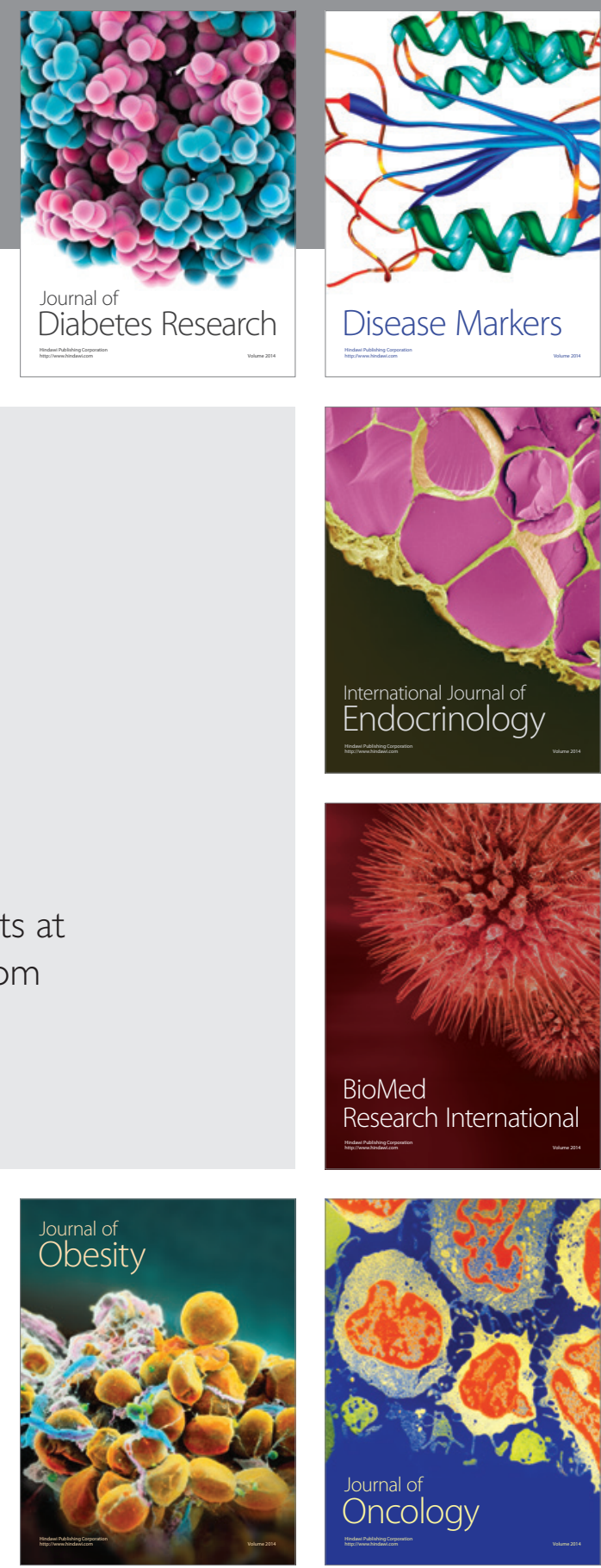

Disease Markers
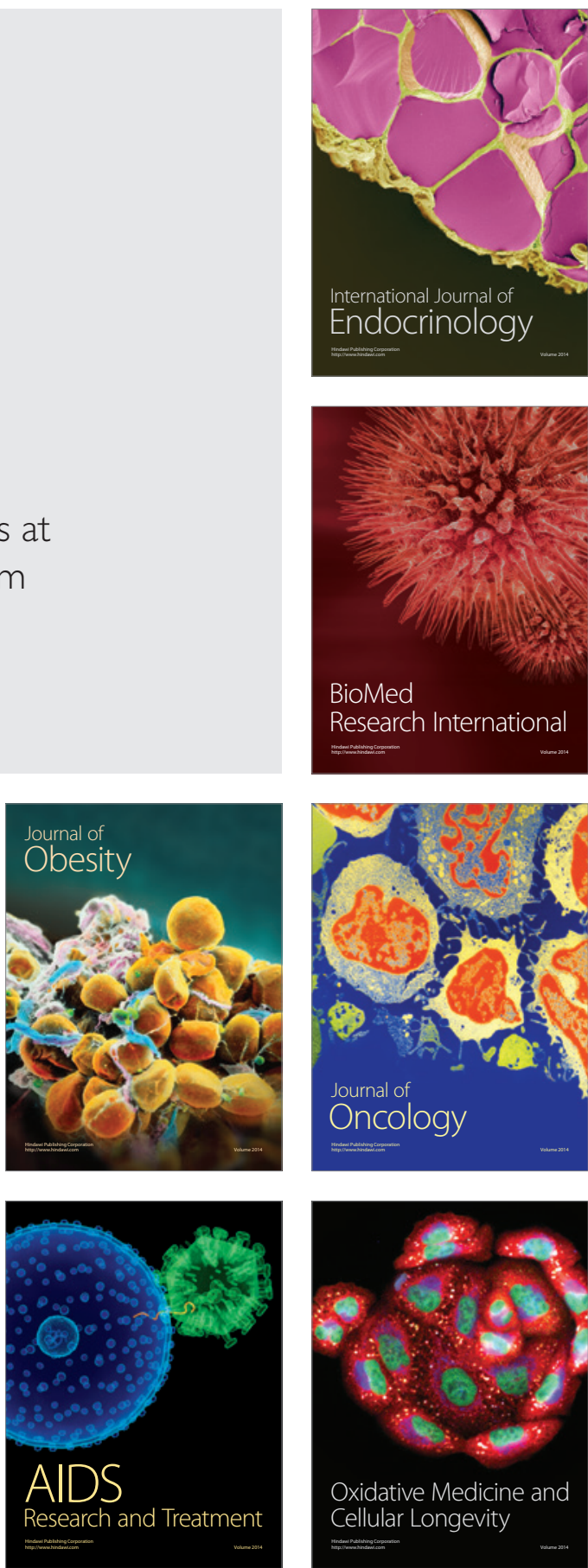